\title{
ANALISIS KINERJA SIMPANG TAK BERSINYAL (Studi Kasus Di Simpang 3 Kudang, Singaparna, Kabupaten Tasikmalaya)
}

\author{
Muhammad Iqbal Sidiq ${ }^{1)}$, Dicky Nurmayadi' ${ }^{2)}$, Farhan Sholahudin ${ }^{3)}$ \\ 1), 2), 3) Jurusan Teknik Sipil, Fakultas Teknik, Universitas Perjuangan Tasikmalaya \\ email: balshy16@gmail.com ${ }^{1)}$, dickynurmayadi@unper.ac.id ${ }^{2}$, \\ farhansholahudin@unper.ac.id ${ }^{3)}$
}

DOI: http://dx.doi.org/10.29103/tj.v11i2.501

(Received: March 2021 / Revised: July 2021 / Accepted: August 2021)

\begin{abstract}
Abstrak
Persimpangan merupakan bagian jalan terpenting yang menghubungkan jaringan jalan. Persimpangan sering terjadi kemacetan di beberapa daerah seperti adanya tundaan dan antrian yang sangat tinggi hingga sering terjadi kemacetan. Salah satu simpang yang sering terjadi macet yaitu di Simpang 3 Kudang yang berada di kecamatan singaparna. Simpang ini sering terjadi tundaan dan antrian yang panjang akibat adanya hambatan samping yang tinggi serta kurangnya lebar jalan pada jalan utama. Oleh karena itu perlu dilakukan analisis kinerja pada persimpangan 3 Kudang untuk diteliti. Penelitian ini bertujuan untuk menganalisis karakteristik dan kinerja simpang. Metode yang digunakan yaitu Metode MKJI 1997. Berdasarkan hasil penelitian selama 1 minggu pada tanggal 05-11 Oktober 2020 didapatkan volume arus lalu lintas jam puncak tertinggi di hari selasa dengan volume $3108 \mathrm{smp} / \mathrm{jam}$, dengan kecepatan kendaraan $<35 \mathrm{~km} / \mathrm{jam}$ dan kepadatan lalu lintas tinggi. Kinerja simpang yang telah dihitung berdasarkan hasil analisis nilai tundaan yaitu tundaan di Jln. Raya Timur Singaparna (Jln.Mayor) di arah barat sebesar 12,77 det/smp dengan tingkat pelayanan $\mathrm{C}$ dan tundaan di arah timur sebesar $10.59 \mathrm{det} / \mathrm{smp}$ dengan tingkat pelayanan B. Untuk tundaan di Jln.K.H.Z. Mustofa (Jln.Minor) di arah selatan sebesar $9.90 \mathrm{det} / \mathrm{smp}$ dengan tingkat pelayanan B. Kesimpulan yang dapat diambil adalah bahwa karakteristik lalu lintas di simpang 3 kudang sangat tinggi, tingkat pelayanan di simpang sampai pada tingkat C. Rekomendasi yang tepat pada kinerja simpang 3 kudang perlu dilakukan pelebaran jalan sebagai prioritas utama serta penambahan rambu lalu lintas dan marka jalan.
\end{abstract}

Kata kunci: Karakteristik lalu lintas, Tundaan, Tingkat pelayanan, Kinerja simpang

\begin{abstract}
Intersections are the most important part of the road connecting the road network. At intersections, traffic jams often occur in several areas, such as delays and very high queues that often cause congestion. One of the intersections that often gets stuck is at intersections 3 Kudang, which is located in the Singaparna district. This intersection often experiences delays and long queues due to high side obstacles and a lack of road width on the main road, therefore it is necessary to analyze the performance at the intersection of 3 Kudang to be investigated. This study aims to analyze the characteristics and performance of the intersection. The method used is the MKJI 1997 method. Based on the results of the study for 1 week on 05-11 October 2020, the highest peak hour traffic volume is on Tuesday with a volume of $3108 \mathrm{pcu} /$ hour, with vehicle speed $<35 \mathrm{~km} \mathrm{/} \mathrm{hour} \mathrm{and} \mathrm{traffic} \mathrm{density.} \mathrm{high} \mathrm{cross.} \mathrm{The} \mathrm{intersection}$
\end{abstract}

Analisis Kinerja Simpang Tak Bersinyal (Studi Kasus di Simpang 3 Kudang, Singaparna, Kabupaten Tasikmalaya) - Muhammad Iqbal Sidiq, Dicky Nurmayadi Farhan Sholahudin 
performance that has been calculated based on the results of the delay value analysis is Delay at Jln. Raya Timur Singaparna (Jln.Mayor) in the west direction of 12.77 $\mathrm{sec} / \mathrm{smp}$ with service level C and delays in the east of $10.59 \mathrm{sec} / \mathrm{smp}$ with service level B. Then for delays at Jln.K.H.Z. Mustofa (Jln.Minor) in the south direction of 9.90 sec/smp with service level B. The conclusion that can be drawn is that the traffic characteristics at the 3 kudang intersection are very high, the level of service at the intersection is up to level $\mathrm{C}$. The right recommendation on the performance of the intersection of 3 kudang needs to be done with road widening as a top priority as well as adding traffic signs and road markings.

Keywords: Traffic characteristics, Delay, Level of service, intersection performance

\section{Latar Belakang}

Singaparna adalah sebuah kecamatan yang berada di wilayah barat, Kabupaten Tasikmalaya, Provinsi Jawa Barat, Indonesia. Kecamatan ini merupakan pusat pemerintahan Kabupaten Tasikmalaya sesuai dengan (Peraturan Pemerintah, 2004). Kecamatan Singaparna memiliki jumlah penduduk 67,942 jiwa, seiring dengan waktu jumlah penduduk yang berada di Kecamatan Singaparna telah meningkat dengan mencapai angka 68,385 jiwa (Badan Pusat Statistik Kabupaten Tasikmalaya, 2019). Berdasarkan data tersebut Kecamatan Singaparna laju pertumbuhan penduduknya semakin bertambah sehingga fasilitas penggunaan jalan untuk kendaraan baik pribadi maupun angkutan umum akan berpengaruh terutama pada kinerja persimpangan.

Kinerja adalah sesuatu yang dicapai, dan lalu lintas adalah gerak kendaraan, orang, hewan di jalan (Intari, 2019). Simpang juga merupakan daerah umum di mana ada dua jalan atau lebih bergabung termasuk jalan (Sriharyani, 2016). Permasalahan yang sering terjadi yaitu di Simpang 3 Kudang Singaparna. Simpang ini adalah simpang sebidang yang merupakan pertemuan simpang bercabang tiga (Zain, 2015) dan simpang tak bersinyal yang merupakan suatu persimpangan yang dalam pengaturannya tidak menggunakan lampu sinyal (Elisabeth, 2015). Salah satu titik kemacetan di Kecamatan Singaparna yaitu adanya pergerakan arus lalu lintas antar kendaraan yang sering berhenti di tikungan yang dapat menimbulkan konflik perpotongan arus kendaraan (Bawangun, 2015) pada simpang terutama kemacetan ini berada pada puncak jam tertentu. Kinerja yang dihadapi pada Simpang 3 Kudang Singaparna Kabupaten Tasikmalaya hingga saat ini masih dirasa belum mencapai maksimal dikarenakan adanya beberapa permasalahan yang dihadapi yaitu diantaranya; 1) Tidak adanya rambu lalu lintas, 2) Ruas jalan pada simpang 3 kudang mempunyai lebar jalan yang sangat minim dengan realita lebar sebesar $5,8 \mathrm{~m}$ jauh dari harapan aturan karena termasuk jalan ruas provinsi di Jl. Raya Timur Singaparna, 3) Adanya arus lalu lintas sebagai ruas jalan kabupaten di Jl. Pahlawan K.H.Z Mustofa yang digunakan sebagai hilir mudik pegawai pemerintah daerah dan padatnya siswa yang melewati jalur tersebut dikarenakan sebagai komplek pendidikan.

Berdasarkan pada pertimbangan tersebut penelitian ini dilakukan. Adapun metode penelitian ini yaitu metode MKJI 1997 sebagai pedoman penelitian pada Simpang Tak Bersinyal. Rumusan masalah ini adalah bagaimana karakteristik lalu lintas, kinerja eksisting, dan rekomendasi untuk kinerja simpang. Tujuan penelitian ini adalah untuk menganalisis karakteristik lalu lintas, kinerja eksisting, memberikan penanganan terhadap kinerja simpang.

Analisis Kinerja Simpang Tak Bersinyal (Studi Kasus di Simpang 3 Kudang, Singaparna, Kabupaten Tasikmalaya) - Muhammad Iqbal Sidiq, Dicky Nurmayadi, Farhan Sholahudin 


\section{Metode Penelitian}

\subsection{Lokasi penelitian}

lokasi penelitian ini dilakukan di simpang 3 kudang Singaparna kabupaten Tasikmalaya. Persimpangan ini merupakan jalan umum/lokal yang sering dilalui kendaraan yang berbeda-beda sepertimdiperlihatkan pada Gambar 1.

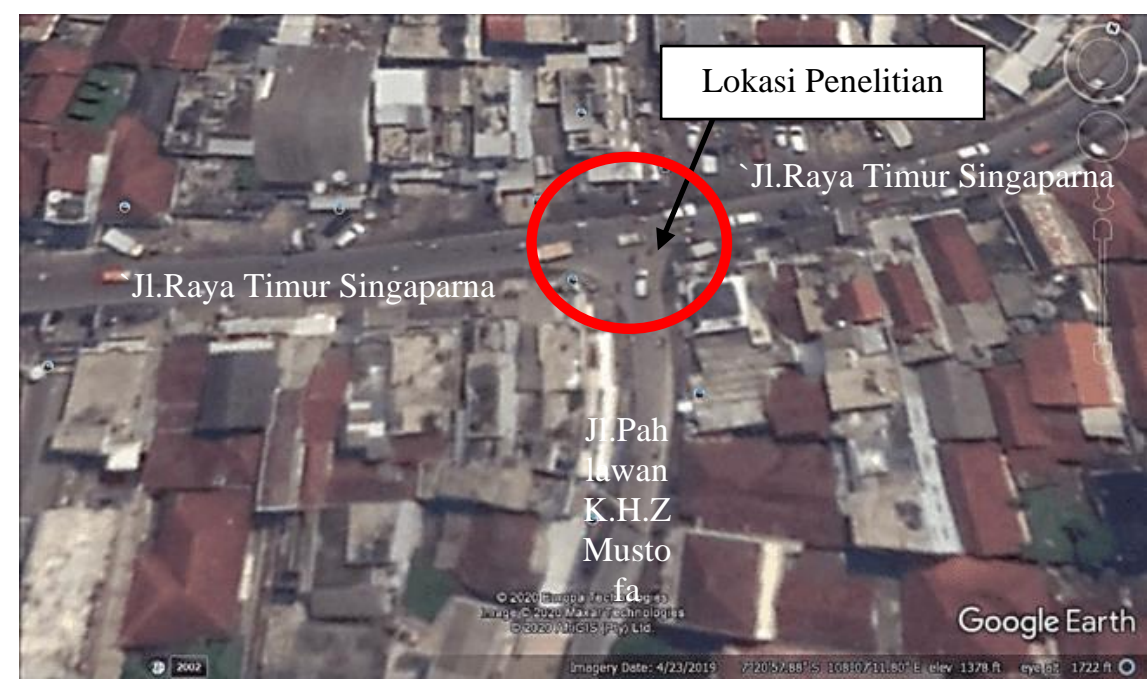

Gambar 1 Lokasi penelitian simpang 3 kudang

\subsection{Pelaksanaan survei}

Pelaksanaan survei di lapangan berupa survei volume kendaraan dan survei kecepatan kendaraan. Survei volume kendaraan dilaksanakan dengan interval 15 menit selama 12 jam untuk mendapatkan jam puncak pada 3 waktu yaitu pagi, siang dan sore. Surveyor dibutuhkan 6 orang untuk melaksanakan pengamatan di lapangan. alat dan cara kerjanya menggunakan aplikasi Multi Counter pada Hand Phone untuk menghitung tiap jenis jenis kendaraan yang lewat.

Survei kecepatan kendaraan dilakukan selama 1 hari berdasarkan sampel dan survei dilakukan pada ruas jalan, surveyor dibutuhkan 3 orang berdasarkan jenis klarifikasi kendaraan yang telah didapatkan saat survei volume kendaraan. Alat dan cara kerjanya menggunakan aplikasi speed gun pada hand phone untuk mengukur kecepatan rata-rata kendaraan dengan menandai tiap satu kendaraan yang bergerak sampai segmen yang ditentukan.

\subsection{Pengumpulan Data}

Pengumpulan data berupa data primer dan data sekunder. Data primer didapatkan dari hasil survei di lapangan secara langsung, data yang diperlukan adalah kondisi geometrik, data kecepatan lalu lintas, volume lalu lintas dan kondisi lingkungan. Data sekunder merupakan data pendukung untuk melengkapi data primer yang diteliti, data sekunder ini berupa data laju pertumbuhan penduduk di Kabupaten Tasikmalaya dan peta lokasi penelitian.

\subsection{Analisis data dengan MKJI 1997}

Berikut ini adalah analisis tahapan perhitungan kinerja simpang tak bersinyal dengan metode MKJI 1997 yaitu (Direktorat Jenderal Bina Marga, 1997):

Analisis Kinerja Simpang Tak Bersinyal (Studi Kasus di Simpang 3 Kudang, Singaparna, Kabupaten Tasikmalaya) - Muhammad Iqbal Sidiq, Dicky Nurmayadi Farhan Sholahudin 
1. Kapasitas

Kapasitas yang ada, C (smp/jam) dihitung dengan menggunakan rumus berikut:

$$
C=C_{O} \times F_{W} \times F_{M} \times F_{C S} \times F_{R S U} \times F_{L T} \times F_{R T} \times F_{M I}
$$

Keterangan:

$C=$ Kapasitas aktual (smp/jam).

$C_{O}=$ Kapasitas dasar.

$F_{W}=$ Faktor penyesuaian lebar masuk.

$F_{M}=$ Faktor penyesuaian median jalan utama.

$F_{C S}=$ Faktor penyesuaian ukuran kota.

$F_{\text {rsu }}=$ Faktor penyesuaian tipe lingkungan, hambatan samping, dan kendaraan tak bermotor.

$F_{L T}=$ Faktor penyesuaian belok kiri.

$F_{R T}=$ Faktor penyesuaian belok kanan.

$F_{M I}=$ Faktor penyesuaian rasio arus jalan minor.

3. Derajat Kejenuhan

Derajat kejenuhan dihitung dengan menggunakan rumus sebagai berikut:

$$
D S=\frac{Q_{T O T}}{C}
$$

Keterangan:

$$
\begin{aligned}
& Q_{T O T}=\text { arus total }(\mathrm{smp} / \mathrm{jam}) . \\
& C=\text { Kapasitas. }
\end{aligned}
$$

4. Tundaan

a. Tundaan lalu lintas simpang $\left(D T_{1}\right)$

$$
\begin{aligned}
& \text { Untuk } D S>0,6: D T_{1}=\frac{1.0504}{(0.274-0.2042 \times D S)}-(1-D S) \times 2 \\
& \text { Untuk } D S \leq 0,6: D T_{1}=2+8,2078 \times D S-(1-D S) \times 2
\end{aligned}
$$

b. Tundaan lalu lintas jalan utama $\left(D T_{M A}\right)$

$$
\begin{aligned}
& \text { Untuk } D S>0,6: D T_{M A}=\frac{1.05034}{0.346-0.246 \times D S}-(1-D S) \times 1.8 \\
& \text { Untuk } D S \leq 0,6: D T_{M A}=1,8+5,8234 \times D S-(1-D S) \times 1,8
\end{aligned}
$$

c. Penentuan tundaan lalu lintas jalan minor $\left(D T_{M I}\right)$

$$
D T_{M I}=\frac{\left(Q_{T O T} \times D_{T I}-Q_{M A} \times D T_{M A}\right)}{Q_{M I}}
$$

d. Tundaan geometrik simpang $(D G)$

$$
\begin{aligned}
& \text { Untuk } D S<1,0: D G=(1-D S) x\left(P_{T} x 6+\left(1-P_{T}\right) \times 3\right)+D S x 4 \\
& \text { Untuk } D S>1,0: D G=1 \\
& \text { e. Tundaan (D) } \\
& \qquad D=D G+D T_{1}(\operatorname{det} / \mathrm{smp})
\end{aligned}
$$

5. Peluang antrian $(Q P \%)$

Peluang antrian, untuk menentukan batas nilai antrian dengan derajat kejenuhan dengan menggunakan rumus sebagai berikut:

$$
\begin{aligned}
& Q P \% \text { batas atas }=47,71 \times D S-24,68 \times D S^{2}+56,47 \times D S^{3} \\
& Q P \% \text { batas bawah }=9,02 \times D S-20,66 \times D S^{2}+10,49 \times D S^{3}
\end{aligned}
$$

6. Level of service (LOS)

Tingkat pelayanan (level of service) pada simpang adalah ukuran kualitas pelayanan persimpangan, yang dapat ditentukan dengan perbandingan antara volume dan kapasitas yaitu tundaan. Berikut ini adalah kiteria LOS (tingkat pelayanan) untuk persimpangan (Badar, 2014). 
Tabel 1 tingkat pelayanan simpang tak bersinyal ((Peraturan Menteri

Perhubungan, 2006)

\begin{tabular}{cc}
\hline Level Of Service $($ LOS $)$ & Tundaan (detik/smp) \\
\hline A & $<5$ \\
\hline B & $5-10$ \\
\hline C & $11-20$ \\
\hline D & $21-30$ \\
\hline E & $31-45$ \\
\hline F & $>45$ \\
\hline
\end{tabular}

\section{Hasil dan Pembahasan}

\subsection{Kondisi Geometrik}

Kondisi geometrik di Simpang 3 Kudang Singaparna Kabupaten Tasikmalaya seperti diperlihatkan pada Gambar 2.

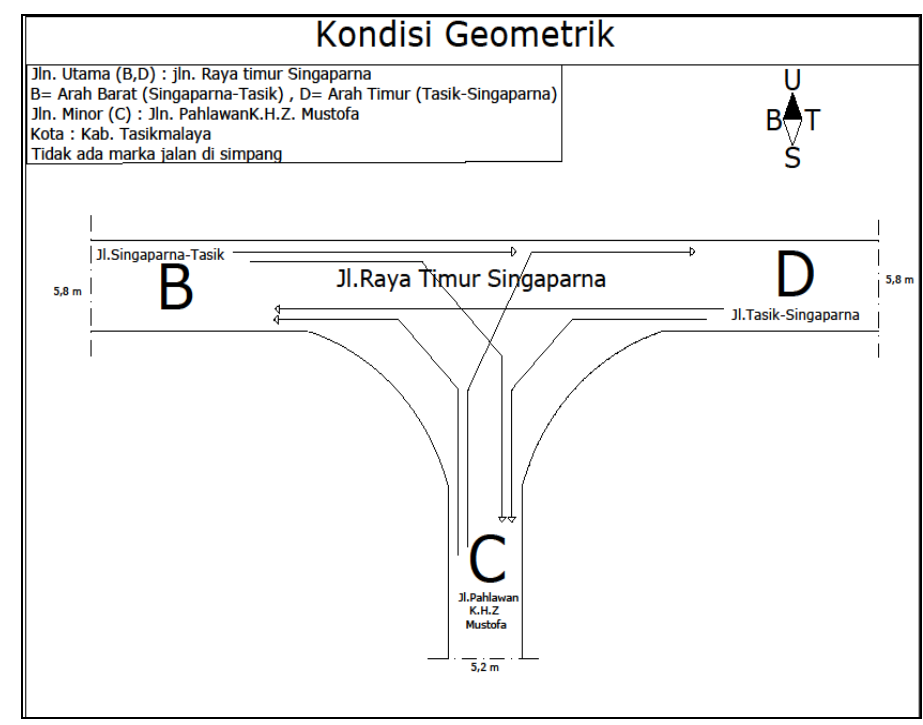

Gambar 2 Kondisi geometrik

\subsection{Volume lalu lintas}

Volume lalu lintas yang diperoleh pada penelitian ini dilakukan selama 1 minggu dengan interval 15 menit selama 12 jam pada pukul 06:00-18:00 WIB per hari. Jam puncak tertinggi pada penelitian ini terjadi pada hari selasa dengan total volume $3108 \mathrm{smp} / \mathrm{jam}$.

Tabel 2 Peak hours dalam 1 minggu

\begin{tabular}{ccccc}
\hline \multirow{2}{*}{ Hari } & Peak Hours & Arah & Volume (smp/jam) & Volume (Kend/jam) \\
\hline Selasa, & & Selatan & 571 & 980 \\
\cline { 3 - 5 } $06-10-2020$ & \multirow{2}{*}{$15: 15-16: 15$} & Timur & 1284 & 1810 \\
\cline { 3 - 5 } & & Barat & 1253 & 1944 \\
\cline { 2 - 4 } & & Total Volume & 3108 & 4734 \\
\hline
\end{tabular}

Berdasarkan hasil analisis data (Tabel 2) bahwa volume peak hours tertinggi terjadi di hari selasa pada pukul 15:15 - 16:15 WIB di sore hari dengan volume sebesar $3108 \mathrm{smp} / \mathrm{jam}$. 


\subsection{Kecepatan}

Kecepatan rata-rata kendaraan yang digunakan merupakan metode kecepatan setempat (spot speed). Berikut hasil penelitian survei kecepatan dapat dilihat pada Tabel dibawah.

Tabel 3 Kecepatan rata-rata kendaraan

\begin{tabular}{lc}
\multicolumn{1}{c}{ Arah } & $\begin{array}{c}\text { Kecepatan Rata }- \text { Rata Semua Kendaraan } \\
(\mathrm{km} / \mathrm{jam})\end{array}$ \\
\hline Barat -Timur (Jalan mayor) & 30.6 \\
\hline Timur - Barat (Jalan mayor) & 29.3 \\
\hline Selatan - Utara (Jalan minor) & 33.7 \\
\hline Utara - Selatan (Jalan minor) & 36.4 \\
\hline
\end{tabular}

Berdasarkan hasil analisis bahwa kecepatan rata-rata kendaraan disimpang pada ruas jalan $<35 \mathrm{~km} / \mathrm{jam}$.

\subsection{Kepadatan}

Berdasarkan volume dan kecepatan kendaraan yang diperoleh maka dapat dihitung kepadatan lalu lintas di simpang dan terjadi pada jalan mayor (utama) seperti diperlihatkan pada Tabel 4.

Tabel 4 Kepadatan lalu lintas

\begin{tabular}{lccc}
\hline Arah & $\begin{array}{c}\text { Arus Lalu Lintas }(\mathrm{Q}) \\
(\mathrm{kend} / \mathrm{jam})\end{array}$ & $\begin{array}{c}\text { Kecepatan }(\mathrm{S}) \\
(\mathrm{km} / \mathrm{jam})\end{array}$ & $\begin{array}{c}\text { Kepadatan }(\mathrm{K}) \\
(\mathrm{kend} / \mathrm{km})\end{array}$ \\
\hline Barat -Timur (Jalan mayor) & 1944 & 30.6 & 64 \\
\hline Timur - Barat (Jalan mayor) & 1810 & 29.3 & 62 \\
\hline Selatan - Utara (Jalan minor) & 980 & 33.7 & 29 \\
\hline Utara - Selatan (Jalan minor) & 367 & 36.4 & 10 \\
\hline
\end{tabular}

\subsection{Kapasitas (C)}

Kapasitas (C) dihitung dengan menggunakan rumus persamaan 1. Berdasarkan hasil analisis bahwa kapasitas tertinggi terjadi di Jl. Raya Timur Singaparna di arah timur dengan notasi D seperti Tabel 5.

Tabel 5 Kapasitas (C)

\begin{tabular}{llllllllll}
\hline & Kapasi & \multicolumn{7}{c}{ Faktor penyesuaian kapasitas (f) } \\
\cline { 3 - 10 } Pilihan & $\begin{array}{l}\text { tas } \\
\text { dasar } \\
(\mathrm{Co})\end{array}$ & $\begin{array}{c}\text { Lebar } \\
\text { pendekat } \\
\text { rata-rata } \\
\left(\mathrm{F}_{\mathrm{W}}\right)\end{array}$ & $\begin{array}{c}\text { Median } \\
\text { jalan } \\
\text { utama } \\
\left(\mathrm{F}_{\mathrm{M}}\right)\end{array}$ & $\begin{array}{c}\text { Ukuran } \\
\text { kota } \\
\left(\mathrm{F}_{\mathrm{CS}}\right)\end{array}$ & $\begin{array}{c}\text { Hambatan } \\
\text { samping } \\
\left(\mathrm{F}_{\mathrm{RSU}}\right)\end{array}$ & $\begin{array}{c}\text { Belok } \\
\text { kiri } \\
\left(\mathrm{F}_{\mathrm{LT}}\right)\end{array}$ & $\begin{array}{c}\text { Belok } \\
\text { kanan } \\
\left(\mathrm{F}_{\mathrm{RT}}\right)\end{array}$ & $\begin{array}{c}\text { Rasio } \\
\text { minor } \\
/ \text { total } \\
\left(\mathrm{F}_{\mathrm{MI}}\right)\end{array}$ & $\begin{array}{c}\text { Kapa } \\
\text { sitas } \\
(\mathrm{C})\end{array}$ \\
\hline $\begin{array}{l}\text { Jl. K.H.Z } \\
\text { Mustofa (C) }\end{array}$ & 2700 & 0.94 & 1.00 & 0.82 & 0.93 & 1.34 & 0.46 & 1.01 & 1202 \\
\hline $\begin{array}{l}\text { Jl. Raya Timur } \\
\text { Singaparna (D) }\end{array}$ & 2700 & 0.94 & 1.00 & 0.82 & 0.93 & 0.91 & 1.09 & 1.01 & 1937 \\
\hline $\begin{array}{l}\text { Jl. Raya Timur } \\
\text { Singaparna (B) }\end{array}$ & 2700 & 0.94 & 1.00 & 0.82 & 0.93 & 0.84 & 0.96 & 1.01 & 1584 \\
\hline
\end{tabular}

\subsection{Derajat kejenuhan}

Derajat kejenuhan dihitung dengan menggunakan rumus persamaan 2 . Berdasarkan hasil analisis bahwa derajat kejenuhan tertinggi terjadi di Jl. Raya Timur Singaparna di arah barat dengan notasi B seperti Tabel 6.

Analisis Kinerja Simpang Tak Bersinyal (Studi Kasus di Simpang 3 Kudang, Singaparna, Kabupaten Tasikmalaya) - Muhammad Iqbal Sidiq, Dicky Nurmayadi, Farhan Sholahudin 
Tabel 6 Derajat kejenuhan (DS)

\begin{tabular}{lccc}
\hline \multicolumn{1}{c}{ Nama Pendekat } & $\begin{array}{c}\text { Arus Lalu Lintas (Q) } \\
\text { smp/jam }\end{array}$ & $\begin{array}{c}\text { Kapasitas (C) } \\
\text { smp/jam }\end{array}$ & $\begin{array}{c}\text { Derajat } \\
\text { Kejenuhan (DS) }\end{array}$ \\
\hline Jl. K.H.Z Mustofa (C) & 571 & 1202 & 0.48 \\
\hline Jl. Raya Timur Singaparna (D) & 1284 & 1937 & 0.66 \\
\hline Jl. Raya Timur Singaparna (B) & 1253 & 1584 & 0.79 \\
\hline
\end{tabular}

\subsection{Tundaan}

Tundaan lalu lintas simpang (DT 1 ), dihitung dengan persamaan 3 dan 4. Berdasarkan hasil analisis tundaaan lalu lintas simpang tertinggi terjadi di Jl. Raya Timur Singaparna di arah barat dengan notasi B sebesar 8.90 det/smp (Tabel 7).

Tabel 7 Tundaan lalu lintas simpang (DT 1 )

\begin{tabular}{lc}
\hline \multicolumn{1}{c}{ Nama Pendekat } & Tundaan Lalu Lintas Simpang (DT ( $_{\mathbf{1}}$ \\
\hline Jl. K.H.Z Mustofa (C) & 4.85 \\
\hline J1. Raya Timur Singaparna (D) & 6.89 \\
\hline Jl. Raya Timur Singaparna (B) & 8.90 \\
\hline
\end{tabular}

Tundaan lalu lintas jalan utama (DT $\mathrm{MA})$, dihitung dengan persamaan 5 dan 6.

Tabel 8 Tundaan lalu lintas jalan utama (DT $\mathrm{MA}$ )

\begin{tabular}{lc}
\hline \multicolumn{1}{c}{ Nama Pendekat } & Tundaan Lalu Lintas Jalan Utama (DTMA) \\
\hline Jl. K.H.Z Mustofa C & 3.64 \\
\hline Jl. Raya Timur Singaparna (D) & 5.13 \\
\hline Jl. Raya Timur Singaparna (B) & 6.55 \\
\hline
\end{tabular}

Berdasarkan hasil analisis bahwa tundaan lalu lintas di jalan utama yaitu di arah barat dengan notasi B sebesar $6.55 \mathrm{det} / \mathrm{smp}$. Penentuan tundaan lalu lintas jalan minor $\left(\mathrm{DT}_{\mathrm{MI}}\right)$, dihitung dengan persamaan 7.

Tabel 9 Penentuan tundaan lalu lintas jalan minor (DT $\left.\mathrm{DI}_{\mathrm{MI}}\right)$

\begin{tabular}{lc}
\hline \multicolumn{1}{c}{ Nama Pendekat } & Tundaan Lalu Linta Jalan Minor (DT \\
\hline Jl. K.H.Z Mustofa (C) & 10.23 \\
\hline Jl. Raya Timur Singaparna (D) & 14.69 \\
\hline J1. Raya Timur Singaparna (B) & 19.29 \\
\hline
\end{tabular}

Berdasarkan hasil analisis bahwa penentuan tundaan lalu lintas jalan minor tertinggi terjadi di Jl. Raya Timur Singaparna di arah barat dengan notasi B sebesar $19.29 \mathrm{det} / \mathrm{smp}$. Tundaan geometrik simpang (DG), dihitung dengan persamaan 8 dan 9 .

Tabel 10 Tundaan geometrik simpang (DG)

\begin{tabular}{lc}
\hline \multicolumn{1}{c}{ Nama Pendekat } & Tundaan Geometrik Simpang (DG) \\
\hline Jl. K.H.Z Mustofa (C) & 5.05 \\
\hline Jl. Raya Timur Singaparna (D) & 3.70 \\
\hline Jl. Raya Timur Singaparna (B) & 3.88 \\
\hline
\end{tabular}

Berdasarkan hasil analisis bahwa tundaan geometrik simpang tertinggi terjadi di Jl. K.H.Z. Mustofa di arah selatan dengan notasi C sebesar $5.05 \mathrm{det} / \mathrm{smp}$.

Analisis Kinerja Simpang Tak Bersinyal (Studi Kasus di Simpang 3 Kudang, Singaparna, Kabupaten Tasikmalaya) - Muhammad Iqbal Sidiq, Dicky Nurmayadi Farhan Sholahudin 
Tundaan Simpang (D), dihitung dengan persamaan 10.

Tabel 11 Tundaan simpang (D)

\begin{tabular}{lc}
\hline \multicolumn{1}{c}{ Nama Pendekat } & Tundaan Simpang (D) (detik/smp) \\
\hline Jl. K.H.Z Mustofa (C) & 9.90 \\
\hline Jl. Raya Timur Singaparna (D) & 10.59 \\
\hline Jl. Raya Timur Singaparna (B) & 12.77 \\
\hline
\end{tabular}

Berdasarkan hasil analisis bahwa tundaan simpang tertinggi terjadi di Jl. Raya Timur Singaparna di arah barat dengan notasi B sebesar $12.77 \mathrm{det} / \mathrm{smp}$.

\subsection{Peluang antrian}

Batas nilai peluang antrian dihitung dengan persamaan 11 dan 12.

Tabel 12 Peluang antrian (QP\%)

\begin{tabular}{lcc}
\hline \multicolumn{1}{c}{ Nama Pendekat } & Derajat Kejenuhan (DS) & Peluang Antrian (QP\%) \\
\hline Jl. K.H.Z Mustofa (C) & 0.48 & $10-23 \%$ \\
\hline Jl. Raya Timur Singaparna (D) & 0.66 & $18-37 \%$ \\
\hline Jl. Raya Timur Singaparna (B) & 0.79 & $25-50 \%$ \\
\hline
\end{tabular}

Berdasarkan hasil analisis bahwa peluang antrian tertinggi terjadi di Jl. Raya Timur Singaparna di arah barat dengan notasi B sebesar 25-50 \%.

\subsection{Level Of Service (LOS)}

Penentuan tingkat pelayanan simpang tak bersinyal seperti pada Tabel 1, ditentukan berdasarkan Nilai Tundaan, untuk menentukan kondisi simpang.

Tabel 13 Tingkat pelayanan simpang 3 kudang

\begin{tabular}{lcc}
\hline \multicolumn{1}{c}{ Nama Pendekat } & Tundaan Simpang (D) & Level OF Service $($ LOS $)$ \\
\hline Jl. K.H.Z Mustofa (C) & 9.90 & $\mathrm{~B}$ \\
\hline Jl. Raya Timur Singaparna (D) & 10.59 & $\mathrm{~B}$ \\
\hline Jl. Raya Timur Singaparna (B) & 12.77 & $\mathrm{C}$ \\
\hline
\end{tabular}

Berdasarkan hasil analisis bahwa tingkat pelayanan tertinggi terjadi pada Jl. Raya Timur Singaparna di arah barat (B) dengan tingkat pelayanan C. Maka sering terjadi kemacetan akibat arus lalu lintasnya tinggi, kecepatan rendah dan kepadatan lalu lintas tinggi.

\subsection{Alternatif Untuk Rekomendasi Simulasi Kinerja Simpang}

Alternatif untuk kinerja simpang 3 kudang adalah dengan memperlebar jalur di jalan utama (mayor) karena ukuran jalurnya sangat kecil dengan ukuran sebesar $5.8 \mathrm{~m}$, dengan menambahkan lebar jalurnya yaitu sebesar $2.2 \mathrm{~m}$ dan jalur pada jalan utama (mayor) menjadi $8 \mathrm{~m}$. Berikut hasil analisis perhitungan:

1). Arah Barat (B)

$$
\begin{array}{ll}
\text { Kapasitas }(\mathrm{C}) & =1678 \mathrm{smp} / \mathrm{jam} . \\
\text { Derajat Kejenuhan }(\mathrm{DS}) & =0.746 \approx 0.75 \\
\text { Tundaan }(\mathrm{D}) & =11.97 \mathrm{det} / \mathrm{smp} . \\
\text { Peluang Antrian }(\mathrm{QP} \%) & =23-45 \% . \\
L O S & =\mathrm{C}
\end{array}
$$


2). Arah Timur (D)

Kapasitas (C) $\quad=2052 \mathrm{smp} / \mathrm{jam}$.

Derajat Kejenuhan $(\mathrm{DS})=0.626 \approx 0.63$

Tundaan $(\mathrm{D}) \quad=10.10 \mathrm{det} / \mathrm{smp}$.

Peluang Antrian $(\mathrm{QP} \%)=16-34 \%$.

$\operatorname{LOS} \quad=\mathrm{B}$

3). Arah Selatan $(\mathrm{C})$

Kapasitas (C) $\quad=1273 \mathrm{smp} / \mathrm{jam}$.

Derajat Kejenuhan $(\mathrm{DS})=0.449 \approx 0.45$

Tundaan $(\mathrm{D}) \quad=9.68 \mathrm{det} / \mathrm{smp}$.

Peluang Antrian $(\mathrm{QP} \%)=9-22 \%$.

$L O S \quad=\mathrm{B}$

\subsection{Hasil analisis data}

Berdasarkan hasil analisis data bahwa kapasitas diperoleh pada rumus persamaan 1, derajat kejenuhan dari rumus persamaan 2, tundaan dari rumus persamaan 10, peluang antrian dari rumus persamaan 11 dan 12 . Berikut adalah hasil perbandingan data eksisting dengan data simulasi pada simpang dapat dilihat pada Tabel dibawah ini:

Tabel 14 Perbandingan hasil perhitungan simulasi pelebaran jalan di jalan mayor

\begin{tabular}{|c|c|c|c|c|c|c|}
\hline \multicolumn{7}{|c|}{ Data Eksisting Perhitungan Kinerja Simpang } \\
\hline Arah & $\begin{array}{l}\text { Lebar } \\
\text { Jalan }\end{array}$ & $\begin{array}{c}\text { Kapasit } \\
\text { as (C) }\end{array}$ & $\begin{array}{c}\text { Derajat } \\
\text { Kejenuhan (DS) }\end{array}$ & $\begin{array}{l}\text { Tundaan } \\
\text { (D) }\end{array}$ & $\begin{array}{l}\text { Peluang Atnrian } \\
(\mathrm{QP} \%)\end{array}$ & $\begin{array}{c}\text { LOS Berdasarkan } \\
\text { Tundaan }\end{array}$ \\
\hline Barat & $5.8 \mathrm{~m}$ & 1584 & 0.791 & 12.77 & $25-50 \%$ & $\mathrm{C}$ \\
\hline Timur & $5.8 \mathrm{~m}$ & 1937 & 0.663 & 10.59 & $18-37 \%$ & $\mathrm{~B}$ \\
\hline Selatan & $5.2 \mathrm{~m}$ & 1202 & 0.475 & 9.90 & $10-23 \%$ & $\mathrm{~B}$ \\
\hline \multicolumn{7}{|c|}{ Data Simulasi Perhitungan Kinerja Simpang } \\
\hline Arah & $\begin{array}{l}\text { Lebar } \\
\text { Jalan }\end{array}$ & $\begin{array}{c}\text { Kapasit } \\
\text { as (C) }\end{array}$ & $\begin{array}{c}\text { Derajat } \\
\text { Kejenuhan (DS) }\end{array}$ & $\begin{array}{l}\text { Tundaan } \\
\text { (D) }\end{array}$ & $\begin{array}{c}\text { Peluang Atnrian } \\
(\mathrm{QP} \%)\end{array}$ & $\begin{array}{c}\text { LOS Berdasarkan } \\
\text { Tundaan }\end{array}$ \\
\hline Barat & $8 \mathrm{~m}$ & 1678 & 0.746 & 11.97 & $23-45 \%$ & $\mathrm{C}$ \\
\hline Timur & $8 \mathrm{~m}$ & 2052 & 0.626 & 10.10 & $16-34 \%$ & $\mathrm{~B}$ \\
\hline Selatan & $5.2 \mathrm{~m}$ & 1273 & 0.449 & 9.68 & $9-22 \%$ & B \\
\hline
\end{tabular}

\section{Kesimpulan dan Saran}

\subsection{Kesimpulan}

Karakteristik lalu lintas didapatkan volume jam puncak tertinggi sebesar 3108 smp/jam, kecepatan rata-rata kendaraan < 35 km/jam dan kepadatan lalu lintas sangat tinggi. Kinerja eksisting tertinggi pada simpang ini terjadi di Jl. Raya Timur Singaparna (Jalan Mayor) pada arah barat dengan kapasitas $1584 \mathrm{smp} / \mathrm{jam}$, derajat kejenuhan 0.791, tundaan $12.77 \mathrm{det} / \mathrm{smp}$, peluang antrian $25-50 \%$ dengan tingkat pelayanan $\mathrm{C}$ bahwa kinerja simpang berada dalam keadaan arus mendekati tidak stabil. Perlu penanganan simpang khususnya pada jalan mayor.

\subsection{Saran}

Berdasarkan dari hasil penelitian diatas dapat diberi saran dan rekomendasi berupa pelebaran jalan pada jalan utama atau jalan besar (mayor) agar kapasitas di perismpangan semakin meningkat. Pemasangan rambu lalu lintas agar pengguna jalan menaati peraturan lalu lintas yang ada serta penggunaan fasilitas halte

Analisis Kinerja Simpang Tak Bersinyal (Studi Kasus di Simpang 3 Kudang, Singaparna, Kabupaten Tasikmalaya) - Muhammad Iqbal Sidiq, Dicky Nurmayadi Farhan Sholahudin 
khusus angkutan umum untuk menaik turunkan penumpang bagi para pelajar atau orang sekitar yang berpergian. Rekomendasi yang tepat pada kinerja simpang tak bersinyal dilakukan pelebaran jalan, rambu lalu lintas dan marka jalan. Prioritas utama dengan hasil akhir melakukan pelebaran jalan utama (mayor).

\section{Daftar Kepustakaan}

Badan Pusat Statistik Kabupaten Tasikmalaya, 2019. Jumlah Penduduk dan Laju Pertumbuhan Penduduk Menurut Kecamatan di Kabupaten Tasikmalaya, 2010, 2016, dan 2017. tasikmalayakab.bps.go.id. Available at: https://tasikmalayakab.bps.go.id/statictable/2019/01/23/62/jumlah-penduduk -dan-laju-pertumbuhan-penduduk-menurut-kecamatan-di-kabupaten-tasik malaya-2010-2016-dan-2017.html, (Accessed: 23 July 2019).

Badar, P. I, 2014. Analisa Persimpangan Tidak Bersinyal Menggunakan Program aaSIDRA. Jurnal Sipil Statik, 2(7), pp. 367-374.

Bawangun, V, 2015. Analisis Kinerja Simpang Tak Bersinyal Untuk Simpang Jalan W.R. Supratman dan Jalan B.W. Lapian Di Kota Manado. Jurnal Sipil Statik, 3(Juni), pp. 422-434.

Direktorat Jenderal Bina Marga, 1997. Highway Capacity Manual Project (HCM), Manual Kapasitas Jalan Indonesia (MKJI). doi: 10.1021/acsami.7b07816.

Elisabeth, L, 2015. Analisis Kinerja Simpang Tanpa Sinyal ( Studi Kasus: Simpang Tiga Ringroad - Maumbi ). 3(7), pp. 515-530.

Intari, D. E, 2019. Analisis Kinerja Simpang Tiga Tak Bersinyal ( Studi Kasus : Simpang Tiga Jalan Raya Serang Km 24 - Jalan Akses Tol Balaraja Barat, Balaraja, Kabupaten Tangerang, Banten). 8(1), pp. 61-69.

Peraturan Menteri Perhubungan, 2006. Peraturan Menhub No. KM 14.

Peraturan Pemerintah, 2004. Peraturan Pemerintah Republik Indonesia nomor 30. Kab.Tasikmalaya. https://peraturan.bpk.go.id/Home/Details/65679/pp-no30-tahun-2004.

Sriharyani, L, 2016. Analisis Kinerja Simpang Tidak Bersinyal Kota Metro (Studi Kasus Persimpangan Jalan, Ruas Jalan Jend. Sudirman, Jalan Sumbawa, Jalan Wijaya Kusuma dan Jalan Inspeksi). 6(1), pp. 8-14. doi: 10.1175/1520-0493(1972)100<0062:SFLS>2.3.CO;2.

Zain, H, 2015. Analisis Kinerja Simpang Tiga Tak Bersinyal (Studi Kasus Simpang Lamlo Kabupaten Pidie). Jurnal Teknik Sipil Unaya, 3(Juni), pp. $422-434$.

Copyright (c) Muhammad Iqbal Sidiq, Dicky Nurmayadi, Farhan Sholahudin

Analisis Kinerja Simpang Tak Bersinyal (Studi Kasus di Simpang 3 Kudang, Singaparna, Kabupaten Tasikmalaya) - Muhammad Iqbal Sidiq, Dicky Nurmayadi, Farhan Sholahudin 